\title{
Association of inflammatory markers and poor outcome in diabetic patients presenting with ST segment elevation myocardial infarction
}

This article was published in the following Dove Press journal:

Journal of Inflammation Research

20 May 2015

Number of times this article has been viewed

\author{
Yulia Belenkova ${ }^{1,2}$ \\ Viktoria Karetnikova ${ }^{1,2}$ \\ Aleksey Diachenko ${ }^{2}$ \\ Olga Gruzdeva' \\ Olga Blagoveshchenskaya ${ }^{3}$ \\ Tatiana Molodtsova ${ }^{3}$ \\ Evgenya Uchasova' \\ Olga Barbarash ${ }^{1,2}$
}

'Federal State Budgetary Institution Research Institute for Complex Issues of Cardiovascular Diseases, Siberian Branch of the Russian Academy of Medical Sciences, ${ }^{2}$ State Budgetary Educational Institution of Higher Professional Education Kemerovo State Medical Academy of the Russian Ministry of Health, ${ }^{3}$ State Budgetary Healthcare Institution Kemerovo Regional Clinical Hospital, Kemerovo, Russian Federation
Correspondence: Evgenya Uchasova Federal State Budgetary Institution Research Institute for Complex Issues of Cardiovascular Diseases, Sciences, 6 Sosnovy Boulevard, Kemerovo 650002, Russian Federation Email evg.uchasova@yandex.ru
Objective: Carbohydrate metabolism disorders (CMD) significantly impact the development and progression of all forms of ischemic heart disease, and inflammation is regarded as a general pathogenetic link between CMD and ischemic heart disease.

Methods: A total of 601 patients with ST segment elevation myocardial infarction (MI) (STEMI), admitted within 24 hours from the onset of symptoms during 1 year, were included in this registry study. The blood levels of inflammation markers were measured at days 10-14 with further follow up at 1 year.

Results: The analysis of acute-phase percutaneous coronary intervention impact on the 1-year outcomes showed that endovascular revascularization significantly improved the 1-year prognosis of STEMI patients both with and without CMD. The analysis of inflammation markers showed significantly higher levels of interleukin (IL)-6 and SCD40L in MI patients with diabetes mellitus, and impaired glucose tolerance. Additionally, the patients with impaired glucose tolerance had significantly higher IL-12 levels. In the diabetic MI patients, the odds ratio of a poor 1-year outcome was high for patients with a high Killip classification of acute heart failure upon admission.

Conclusion: Persistent inflammation in STEMI patients with CMD undergoing percutaneous coronary intervention might be responsible for vascular complications within 1 year after MI. Comorbid diabetes mellitus or impaired glucose tolerance can amplify the significance of the inflammatory response for the development of adverse 1-year outcomes.

Keywords: carbohydrate metabolism disorders, inflammation percutaneous coronary intervention

\section{Background}

Carbohydrate metabolism disorders (CMD) are thought, not only to contribute to the development of all forms of ischemic heart disease (IHD) but also, to significantly impact the prognosis. ${ }^{1}$ According to some authors, hospital and posthospital mortality in myocardial infarction (MI) patients is significantly higher if they have diabetes mellitus (DM), ${ }^{2,3}$ despite contemporary treatment modalities aimed at coronary flow restoration.

Revascularization procedures in acute MI can help optimize the prognosis in this patient category. ${ }^{4,5}$ However, a history of DM remains a risk factor for adverse cardiovascular events after primary percutaneous coronary intervention (PCI), despite encouraging results. ${ }^{6}$ Moreover, data have demonstrated a negative impact from impaired glucose tolerance (IGT) on the prognosis of MI patients, which is comparable with that of DM. ${ }^{7,8}$ 
Inflammation is regarded as a general pathogenetic link between CMD and IHD. Indeed, recent data have demonstrated that the increase in the levels of a range of nonspecific markers is associated with a higher risk of IHD and a poor outcome if the disease is already established. ${ }^{9}$ In an earlier manuscript published by the authors, high levels of some inflammation markers were demonstrated to be characteristic of, not only diabetic MI patients but also, those with IGT. This finding suggests that inflammation might be the leading mechanism responsible for the development of adverse cardiovascular events in both symptomatic and asymptomatic patients with CMD. ${ }^{10}$ However, the most significant inflammation markers to assess risk in MI patients with CMD undergoing PCI remain disputable. This study aimed to assess the significance of nonspecific inflammation markers to assess the risk for a poor 1-year outcome in patients with ST segment elevation MI (STEMI) and type 2 DM or IGT undergoing PCI.

\section{Methods}

The study protocol was approved by the local ethics committee of the Federal State Budgetary Institution Research Institute for Complex Issues of Cardiovascular Diseases, of the Siberian Branch of the Russian Academy of Medical Sciences and was developed according to the World Medical Association Declaration of Helsinki Ethical Principles for Medical Research Involving Human Subjects (2008 edition), ${ }^{11}$ and the "Good Clinical Practice Principles in the Russian Federation" approved by the Russian Ministry of Health Order. All patients signed an informed consent before taking part in the study.

The inclusion criterion was STEMI within 24 hours from the onset, with no age restrictions. The exclusion criteria were: MI occurring during PCI or coronary artery bypass surgery; end-stage renal failure; known cancer; worsening of any chronic disease; or any other disease that significantly limited the life expectancy.

\section{Patient population}

A total of 601 STEMI patients admitted over 1 year, within 24 hours from the onset of symptoms, were included into this registry study. The mean age was 62.90 (32.0-94.0) years. The medical history and clinical data as well as the main characteristics of the MI index and hospital treatment are summarized in Table 1.

\section{Glucose tolerance test}

All patients had their blood glucose levels assessed upon admission. At days 8-14, the patients with no known CMD
Table I Clinical and medical history data of the STEMI patients $(n=60 I)$

\begin{tabular}{|c|c|}
\hline \multicolumn{2}{|l|}{ Parameters } \\
\hline Female sex, n (\%) & $226(37.6 I)$ \\
\hline Age, years & $62.90(61.99 ; 63.81)$ \\
\hline Smoking, n (\%) & $24 I(40.09)$ \\
\hline Arterial hypertension, $\mathrm{n}(\%)$ & $537(89.35)$ \\
\hline Diabetes mellitus, $n$ (\%) & $140(23.29)$ \\
\hline Impaired glucose tolerance, n (\%) & $32(5.32)$ \\
\hline History of myocardial infarction, n (\%) & $166(27.62)$ \\
\hline History of angina pectoris, $n(\%)$ & $354(58.90)$ \\
\hline History of stroke, n (\%) & $64(10.64)$ \\
\hline Obesity (BMI > 25 kg/m²), n (\%) & $427(71.04)$ \\
\hline Left ventricular ejection fraction, $\%$ & 48.97 (48.II; 49.84) \\
\hline LV dysfunction (LVEF <46\%), n (\%) & I6I (26.78) \\
\hline Killip class upon admission (II-IV), $\mathrm{n}(\%)$ & $123(20.46)$ \\
\hline Mean TIMI score & $3.94(3.7 I ; 4.16)$ \\
\hline Coronary angiography, n (\%) & $436(72.54)$ \\
\hline \multicolumn{2}{|l|}{ Reperfusion, $\mathrm{n}(\%)$} \\
\hline Stenting & $30 I(50.08)$ \\
\hline Balloon angioplasty & $75(12.47)$ \\
\hline Intracoronary TLT & $14(2.32)$ \\
\hline \multicolumn{2}{|l|}{ Hospital medications, n (\%) } \\
\hline Antiplatelets & $567(94.34)$ \\
\hline$\beta$-blockers & $509(84.69)$ \\
\hline ACE inhibitors & $510(84.85)$ \\
\hline Diuretics & $240(39.93)$ \\
\hline Statins & $152(25.29)$ \\
\hline Calcium channel blockers & $395(65.72)$ \\
\hline
\end{tabular}

Notes: The values given in the brackets are the median (QI;Q3).

Abbreviations: ACE, angiotensin-converting-enzyme inhibitor; BMI, body mass index; LV, left ventricular; LVEF, left ventricular ejection fraction; STEMI, ST segment elevation myocardial infarction; TIMI, Thrombolysis in Myocardial Infarction; TLT, thrombolytic therapy.

and fasting or postprandial glucose levels of $<11.1 \mathrm{mmol} / \mathrm{L}$ were subjected to an oral glucose tolerance test (OGTT) (the World Health Organization recommendation ${ }^{12}$ is for a $75 \mathrm{~g}$ of glucose oral dose in all adults. The dose should be drunk within 5 minutes).

A diagnosis of DM was documented if it was present in the patients' medical records. ${ }^{12}$ New-onset type 2 DM was diagnosed during the hospital stay, based on the repeat glucose test results and OGTT findings; IGT was diagnosed during the hospital stay, based on the OGTT results. ${ }^{8}$

The diagnosis of diabetes was based on two or more independent determinations (on different days) of the glucose level that were $\geq 7.0 \mathrm{mmol} / \mathrm{L}$ (126 mg/dL). In doubtful cases, such as the presentation of characteristic clinical picture of diabetes with fasting plasma glucose within 6.6-7.7 mmol/L, OGTT was performed; patients with OGTT $\geq 11.1 \mathrm{mmol} / \mathrm{L}$ were diagnosed with type $2 \mathrm{DM}$. In addition, type $2 \mathrm{DM}$ was raised when glycated hemoglobin $\left(\mathrm{HbA}_{1 \mathrm{c}}\right) \geq 6.5 \%$ (according to the recommendations of American Diabetes Association). ${ }^{12}$ 


\section{Therapy}

In the hospital, the patients received the therapy recommended by the 2007 National Society of Cardiology (VNOK) guidelines ${ }^{13}$ on STEMI diagnosis and treatment. The reperfusion strategy was determined as soon as possible for all patients, including: balloon angioplasty; stenting of the infarct-related artery; or intracoronary thrombolytic therapy (TLT). Systemic TLT was performed if emergency coronary angiography was contraindicated. The main contraindication for TLT was late admission (more than 12 hours from the disease onset), and PCI was contraindicated if diffuse coronary lesions were present and the infarct-related artery could not be determined.

The total extent of coronary artery disease was assessed by the Syntax score ${ }^{14}$ while considering the lesion location and a range of morphologic characteristics (occlusion, bifurcation, ostial stenosis, prolonged lesion, calcinosis, intracoronary thrombosis, etc) ${ }^{15}$ using the online calculator. ${ }^{16}$

In this study, coronary angiography was performed in 436 (72.55\%) STEMI patients. Based on the obtained data, $373(62.06 \%)$ patients underwent primary PCI for the index MI (Table 1), and a noninvasive treatment strategy was chosen for 228 (37.94\%) patients. Out of 373 patients that underwent successful PCI, stents were implanted in 301 $(80.70 \%)$ patients; $14(3.75 \%)$ and $75(20.10 \%)$ patients had intracoronary thrombolysis and balloon angioplasty (percutaneous transluminal coronary angioplasty) performed, respectively.

A total of 59 (9.81\%) patients died during the hospital stay; all deaths were due to MI complications (heart ruptures, cardiogenic shock, or lung edema). In all, 15 (25.42\%) deceased patients were diabetic, and two (3.38\%) individuals had IGT.

During the hospital stay, all patients were administered combined coronaroactive and antithrombotic therapy (anticoagulants, antiplatelet agents, beta-blockers, angiotensin-converting-enzyme inhibitor (ACE) inhibitors, statins, and calcium channel blockers) according to individual indications. All patients with documented CMD received medical counseling about lifestyle modifications, including sufficient physical exercise (depending on the time from MI onset), diet, and body weight reduction; if indicated, glucoselowering medications (biguanides) were recommended, and the insulin dose was adjusted, if necessary.

The 1-year outcome was assessed in 470 (86.72\%) patients; a total $72(13.28 \%)$ patients were lost to follow up. In all, 155 (32.98\%) end points, including 59 (12.55\%) deaths, $86(18.30 \%)$ recurrent MIs, $52(11.06 \%)$ cases of unstable angina, 18 (3.83\%) strokes, 20 (4.26\%) hospital admissions for heart failure, and 40 (8.51\%) emergency PCIs were registered during the study. The causes of deaths during hospital stay were early complications of MI - cardiorrhexis, pulmonary edema, and cardiogenic shock. During the year, the fatality in $56(94.92 \%)$ cases had cardiovascular causes - development of reinfarction, augmentation of chronic heart failure (pulmonary edema), stoke development, and ventricular arrhythmias. In other cases, fatality occurred in two $(3.39 \%)$ patients with oncopathology and in one $(1.69 \%)$ patient, as a result of a road traffic accident.

\section{Assays}

Blood serum and plasma were tested. The serum was separated from venous blood by centrifugation at $3,000 \times$ $g$ for 20 minutes and stored at $-70^{\circ} \mathrm{C}$. The blood levels of inflammation markers (fibrinogen, interleukin [IL]-6, IL-8, IL-12, tumor necrosis factor [TNF]- $\alpha$, high-sensitivity C-reactive protein [hsCRP], and $\mathrm{sCD} 40 \mathrm{~L}$ ) were measured at days 10-14, with further follow up at year 1, to determine the clinical significance of inflammation markers in predicting cardiovascular events after PCI. Cytokine Quantikine ${ }^{\mathbb{B}}$ (R\&D Systems, Inc., Minneapolis, MN, USA) tests were used, for: human IL- 6 (sensitivity $=0.16 \mathrm{ng} / \mathrm{mL}$; intra- and interassay precision, coefficients of variation $[\mathrm{CV}]=5.7$ and $8.2 \%$ ), human IL-8 (sensitivity $=0.011 \mathrm{ng} / \mathrm{mL}$, intra- and interassay precision; $\mathrm{CV}=4.4$ and $7.3 \%$ ), human IL-12 (sensitivity $=0.011 \mathrm{ng} / \mathrm{mL}$, intra- and interassay precision; $\mathrm{CV}=4.4$ and $7.3 \%$ ), human TNF- $\alpha$ (sensitivity $=9.0 \mathrm{pg} /$ $\mathrm{mL}$, intra- and interassay precision; $\mathrm{CV}=4.5$ and $7.0 \%$ ), and $\mathrm{SCD} 40 \mathrm{~L}$ (sensitivity $=0.12 \mathrm{ng} / \mathrm{mL}$, intra- and interassay precision; $\mathrm{CV}=6.4$ and $11.4 \%$ ). hsCRP was analyzed by means of solid-phase enzyme immunoassay (EIA), using a BioMedica kit (Waterloo, NSW, Australia) (sensitivity $=0.12$ $\mathrm{ng} / \mathrm{mL}$, intra- and interassay precision; $\mathrm{CV}=6.1$ and $9.4 \%$ ). The risk of death or myocardial infarction in patients assessed by TIMI Risk Score. ${ }^{17}$

\section{Statistical analysis}

The data were statistically processed using SPSS Statistics for Windows, Version 21.0 (IBM Corp, Armonk, NY, USA) software. The Shapiro-Wilk test was used to assess the normality of continuous data. Most of the data had statistically significant deviations from the normal distribution; therefore, $\mathrm{Me}\left(\mathrm{Q}_{1} ; \mathrm{Q}_{3}\right)$ was used, where Me was the median, and $25 \%-75 \%$ was the interquartile range that comprised $50 \%$ of the data on both sides of the median. The nonparametric 
Mann-Whitney $U$-test was used to test the hypothesized differences between the samples. The differences between the categorical variables in the mismatched samples were analyzed using $\chi^{2}$ test, with Yates' correction for continuity. The frequency of the properties in the groups was analyzed by means of the odds ratio calculation. $P<0.05$ was considered statistically significant.

\section{Results}

With regard to the presence of CMD, STEMI patients were divided into three groups: normal blood glucose $(n=429$ [71.38\%]); IGT ( $n=32$ [5.33\%]); and DM ( $n=140$ [23.29\%]), of which 16 (11.42\%) had new-onset DM.

The analysis of medical history and clinical characteristics of STEMI patients with regard to CMD showed that the "most severe" group included diabetic patients, while the "least severe" group included those with normal blood glucose levels, and IGT patients comprised a "borderline" group (Table 2). Diabetic patients more often had arterial hypertension, a history of MI, angina pectoris, and congestive heart failure (CHF); these patients also more often had high Thrombolysis in Myocardial Infarction (TIMI) scores, were admitted to the hospital for CHF, had Killip III or IV scores, ${ }^{18}$ and had higher rates of rethrombosis during their hospital stay. The IGT group, compared with the diabetic patients and those with normal blood glucose levels, more often included obese patients and those with a history of CHF and stroke. Additionally, the groups of STEMI patients with DM and IGT included more women than did the group comprised of patients with normal blood glucose levels.

MI patients with DM and IGT had a more extensive coronary artery disease (Syntax score) compared with the patients with normal blood glucose, who also had severe coronary lesions; however, these differences were not statistically significant (Table 2 ).

Coronary angiography only or PCI did not result in statistically significant differences (Table 3).

During the hospital stay, the diabetic STEMI patients more often developed early postinfarction angina, rethrombosis, and recurrent MI compared with the patients with normal blood glucose (Table 4). Similar to the diabetic patients, IGT patients also had higher rates of early postinfarction angina and recurrent MI compared with those who had normal blood glucose.

The analysis of 1-year outcomes showed that the diabetic patients had 1.5 -fold more end points $(P=0.005)$ than did patients with normal blood glucose and 1.3-fold more end points than did the IGT patients (Table 5). Despite the lack of differences in the rate of end points between the MI patients with IGT and those with normal blood glucose, the IGT group had the highest admission rates for unstable angina and more often underwent emergency revascularization within 1 year. Thus, the presence of DM and IGT in $\mathrm{MI}$ patients determines a more complicated course of index MI.

The analysis of the impact of acute-phase PCI on 1-year outcomes showed that endovascular revascularization significantly improved the 1-year prognosis of STEMI patients, both with and without CMD (Table 6). The benefits of a restored coronary flow were especially evident in STEMI patients with DM or IGT. CMD patients had significantly less adverse events within a year after the index MI compared with those with normal blood glucose. In this regard, the progression of the IGT postinfarction was similar to that of the diabetic patients.

Thus, the study results demonstrate that both DM and IGT in MI patients equally determine, not only a more complicated course of the disease but also, a poor 1-year outcome. Moreover, PCI in STEMI patients with DM or IGT represents a significant prognostic benefit in terms of the reduction of adverse events within 1 year.

The analysis of inflammation markers showed significantly higher levels of IL-6 and sCD40L in the MI patients with DM and IGT. Additionally, the IGT patients had significantly higher IL-12 levels compared with the patients with normal blood glucose (Table 7).

The odds ratios (OR) were calculated to determine the factors that implicate a poor 1-year failure, including, left ventricular (LV) dysfunction, high levels of inflammation markers (TNF- $\alpha$, IL-12, and IL-6) at days 10-14 from MI onset, admission glucose levels of $>7.8 \mathrm{mmol} / \mathrm{L}$, and recurrent in-hospital MI.

In the diabetic MI patients, the OR of a poor 1-year outcome was high for patients with a high Killip class of acute heart failure upon admission, a history of chronic heart failure, LV dysfunction, and high IL-12 levels. In the IGT group, the factors associated with adverse outcomes were a history of angina pectoris, admission glucose levels of $>7.8 \mathrm{mmol} / \mathrm{L}$, and high IL-12 levels (Table 8). Prognostically unfavorable levels of inflammation markers and glucose were calculated, along with the most optimal sensitivity and specificity.

For all STEMI patients, the OR of a poor 1-year outcome was significant if PCI was not performed. The OR method was also used to compare the efficacy of endovascular revascular- 
Table 2 Clinical and medical history data of the STEMI patients with regard to carbohydrate metabolism disorders

\begin{tabular}{|c|c|c|c|c|}
\hline Parameters & Normal glucose $^{a}(n=429)$ & $D M^{b}(n=\mid 40)$ & $\operatorname{IGT}^{c}(n=32)$ & $P$-value \\
\hline \multirow[t]{3}{*}{ Mean age, years } & $61.0(53.0 ; 72.0)$ & $66.0(58.0 ; 71.0)$ & $59.5(54.0 ; 69.0)$ & $P=0.106^{a, b}$ \\
\hline & & & & $P=0.304^{\mathrm{a}, \mathrm{c}}$ \\
\hline & & & & $P=0.027^{b, c}$ \\
\hline \multirow[t]{3}{*}{ Female sex, n (\%) } & $123(28.67)$ & $86(6 I .42)$ & $17(53.12)$ & $P \leq\left. 0.00\right|^{a, b}$ \\
\hline & & & & $P=0.007^{a, c}$ \\
\hline & & & & $P=0.506^{\mathrm{b}, \mathrm{c}}$ \\
\hline \multirow[t]{3}{*}{ Arterial hypertension, n (\%) } & $375(87.4 I)$ & $133(95.0)$ & $29(90.62)$ & $P=0.018^{a, b}$ \\
\hline & & & & $P=0.592^{\mathrm{a}, \mathrm{c}}$ \\
\hline & & & & $P=0.799^{b, c}$ \\
\hline \multirow[t]{3}{*}{ Obesity, n (\%) } & $282(65.73)$ & $116(87.22)$ & $29(90.62)$ & $P \leq\left. 0.00\right|^{a, b}$ \\
\hline & & & & $P=0.027^{a, c}$ \\
\hline & & & & $P=0.819^{b, c}$ \\
\hline \multirow[t]{3}{*}{ History of MI, n (\%) } & $104(24.24)$ & $52(37.14)$ & $10(31.25)$ & $P=0.004^{a, b}$ \\
\hline & & & & $P=0.500^{a, c}$ \\
\hline & & & & $P=0.673^{2,3}$ \\
\hline \multirow[t]{3}{*}{ History of angina pectoris, $\mathrm{n}(\%)$} & $229(53.37)$ & $103(73.57)$ & $22(68.75)$ & $P \leq 0.00 I^{a, b}$ \\
\hline & & & & $P=0.134^{\mathrm{a}, \mathrm{c}}$ \\
\hline & & & & $P=0.740^{b, c}$ \\
\hline \multirow[t]{3}{*}{ History of CHF, n (\%) } & 27 (6.29\%) & 14 (10.0\%) & $3(9.37 \%)$ & $P=0.027^{a, b}$ \\
\hline & & & & $P=0.673^{a, c}$ \\
\hline & & & & $P=0.506^{b, c}$ \\
\hline \multirow[t]{3}{*}{ History of stroke, n (\%) } & $36(8.39)$ & $21(15.0)$ & $7(21.87)$ & $P=0.036^{a, b}$ \\
\hline & & & & $P=0.027^{a, c}$ \\
\hline & & & & $P=0.493^{b, c}$ \\
\hline \multirow[t]{3}{*}{ Smoking, n (\%) } & $188(43.82)$ & $31(22.14)$ & $22(68.75)$ & $P \leq\left. 0.00\right|^{a, b}$ \\
\hline & & & & $P=0.01 I^{a, c}$ \\
\hline & & & & $P \leq\left. 0.00\right|^{b, c}$ \\
\hline \multirow[t]{3}{*}{ LVEF, \% } & $50.0(43.0-56.0)$ & $49.0(44.0-55.0)$ & $48.50(40.0-55.50)$ & $P=0.535^{a, b}$ \\
\hline & & & & $P=0.734^{\mathrm{a}, \mathrm{c}}$ \\
\hline & & & & $P=0.983^{b, c}$ \\
\hline LV dysfunction (LVEF <46\%), & $136(3 \mid .70)$ & $4 \mathrm{I}(29.29)$ & $10(31.25)$ & $P=0.666^{a, b}$ \\
\hline \multirow[t]{2}{*}{ n (\%) } & & & & $P=0.960^{a, c}$ \\
\hline & & & & $P=0.996^{\mathrm{b}, \mathrm{c}}$ \\
\hline \multicolumn{5}{|l|}{ MI localization, n (\%) } \\
\hline Anterior MI & 205 (47.79) & $70(50.0)$ & $19(59.38)$ & $P=0.006^{a, b}$ \\
\hline Posterior MI & $200(46.62)$ & $55(39.29)$ & $13(40.62)$ & $P=0.4 \mid 6^{\mathrm{a}, \mathrm{c}}$ \\
\hline $\begin{array}{l}\text { Posterior MI with the right } \\
\text { ventricle affected }\end{array}$ & $10(2.33)$ & I $(0.7 \mathrm{I})$ & $0(0)$ & $P=0.274^{b, c}$ \\
\hline Circular MI & $14(3.26)$ & $4 \mid 4(10.0)$ & $0(0)$ & \\
\hline \multicolumn{5}{|l|}{ Killip class upon admission, $\mathrm{n}(\%)$} \\
\hline 1 & $331(77.16)$ & 90 (64.29) & $20(62.50)$ & $P \leq\left. 0.00\right|^{a, b}$ \\
\hline II & $70(16.32)$ & $22(|5.7|)$ & $10(31.25)$ & $P=0.109^{a, c}$ \\
\hline III & $16(3.73)$ & $21(15.0)$ & $2(6.25)$ & $P=0.090^{b, c}$ \\
\hline IV & $12(2.79)$ & $7(5.0)$ & $0(0)$ & \\
\hline \multirow[t]{3}{*}{ Mean TIMI score } & $3.0(2.0 ; 6.0)$ & $4.0(2.0 ; 6.0)$ & $3.5(2.0 ; 6.0)$ & $P=0.184^{a, b}$ \\
\hline & & & & $P=0.934^{\mathrm{a}, \mathrm{c}}$ \\
\hline & & & & $P=0.857^{b, c}$ \\
\hline \multirow[t]{3}{*}{ SYNTAX } & $17.65(15.34 ; 20.05)$ & $21.04(17.56 ; 23.78)$ & $18.22(15.82 ; 22.15)$ & $P=0.262^{a, b}$ \\
\hline & & & & $P=0.653^{a, c}$ \\
\hline & & & & $P=0.506^{b, c}$ \\
\hline
\end{tabular}

Notes: agroup with normal glucose. 'broup with diabetes mellitus. 'group with impaired glucose tolerance.

Abbreviations: CHF, congestive heart failure; DM, diabetes mellitus; IGT, impaired glucose tolerance; LV, left ventricular; LVEF, left ventricular ejection fraction; MI, myocardial infarction; STEMI, ST segment elevation myocardial infarction; TIMI, Thrombolysis in Myocardial Infarction.

ization in the study groups. To this end, the STEMI patients that underwent PCI were considered to be the exposed subgroup, and the controlled event - the incidence of which depended on the exposing factor-was the occurrence of end points within the 1-year follow-up period. The data presented in this study showed that revascularization procedures in the acute MI phase helped to optimize the 1-year outcome in all of the three patient groups $(\mathrm{OR}=0.33, P<0.0001$ [normal 
Table 3 Main characteristics of hospital coronary interventions for the STEMI patients with regard to carbohydrate metabolism disorders

\begin{tabular}{|c|c|c|c|c|}
\hline Parameters & $\begin{array}{l}\text { Normal } \\
\text { glucose }^{a} \\
(n=429)\end{array}$ & $\begin{array}{l}D M^{b} \\
(n=\mid 40)\end{array}$ & $\begin{array}{l}\text { IGT }^{c} \\
(n=32)\end{array}$ & $P$-value \\
\hline $\begin{array}{l}\text { Coronary } \\
\text { angiography, } \\
n(\%)\end{array}$ & 309 (72.03) & 104 (74.29) & $23(71.87)$ & $\begin{array}{l}P=0.681^{a, b} \\
P=0.960^{a, c} \\
P=0.955^{b, c}\end{array}$ \\
\hline PCl, n (\%) & $274(63.87)$ & $79(56.43)$ & $20(62.50)$ & $\begin{array}{l}P=0.140^{a, b} \\
P=0.960^{a, c} \\
P=0.668^{b, c}\end{array}$ \\
\hline Stenting, n (\%) & $219(51.05)$ & $66(47.14)$ & $16(50.0)$ & $\begin{array}{l}P=0.481^{a, b} \\
P=0.960^{a, c} \\
P=0.924^{b, c}\end{array}$ \\
\hline $\begin{array}{l}\text { Balloon } \\
\text { angioplasty, } \\
\text { n (\%) } \\
\text { TLT, n (\%) }\end{array}$ & $58(13.52)$ & $12(8.57)$ & $5(15.62)$ & $\begin{array}{l}P=0.162^{a, b} \\
P=0.946^{a, c} \\
P=0.380^{b, c}\end{array}$ \\
\hline Systemic & $35(8.16)$ & II (7.86) & $3(9.38)$ & $P=0.729^{a, b}$ \\
\hline Intracoronary & II (2.56) & $2(1.43)$ & I (3.12) & $\begin{array}{l}P=\left.0.95\right|^{a, c} \\
P=0.766^{b, c}\end{array}$ \\
\hline
\end{tabular}

Notes: agroup with normal glucose. bgroup with diabetes mellitus. 'group with impaired glucose tolerance.

Abbreviations: DM, diabetes mellitus; IGT, impaired glucose tolerance; $\mathrm{PCl}$, percutaneous coronary intervention; STEMI, ST segment elevation myocardial infarction; TLT, thrombolytic therapy.

blood glucose group]; OR $=0.23, P=0.039$ [DM group]; and OR $=0.20, P=0.022$ [IGT group]). However, the efficacy of PCI was much higher in both the ITG and in the DM groups than in the normal blood glucose patients.

Table 4 Hospital outcome of the STEMI patients with regard to carbohydrate metabolism disorders

\begin{tabular}{|c|c|c|c|c|}
\hline Parameters & $\begin{array}{l}\text { Normal } \\
\text { glucose }^{a} \\
(n=429)\end{array}$ & $\begin{array}{l}D^{b} \\
(n=\mid 40)\end{array}$ & $\begin{array}{l}I^{\prime G T} T^{c} \\
(n=32)\end{array}$ & $P$-value \\
\hline $\begin{array}{l}\text { Composite hospital } \\
\text { end points, } n(\%)\end{array}$ & 81 (18.88) & $36(25.7 I)$ & $7(21.87)$ & $\begin{array}{l}P=0.106^{\mathrm{a}, \mathrm{b}} \\
P=0.855^{\mathrm{a}, \mathrm{c}} \\
P=0.82 \mathrm{I}^{\mathrm{b}, \mathrm{c}}\end{array}$ \\
\hline Hospital death, n (\%) & $42(9.79)$ & $15(10.7 I)$ & $2(6.25)$ & $\begin{array}{l}P=0.878^{\mathrm{a}, \mathrm{b}} \\
P=0.730^{\mathrm{a}, \mathrm{c}} \\
P=0.663^{\mathrm{b}, \mathrm{c}}\end{array}$ \\
\hline $\begin{array}{l}\text { Restenosis/ } \\
\text { rethrombosis, n (\%) }\end{array}$ & $15(3.50)$ & $16(11.43)$ & $2(6.25)$ & $\begin{array}{l}P=0.00 I^{\mathrm{a}, \mathrm{b}} \\
P=0.756^{\mathrm{a}, \mathrm{c}} \\
P=0.587^{\mathrm{b}, \mathrm{c}}\end{array}$ \\
\hline $\begin{array}{l}\text { Early postinfarction } \\
\text { angina, } \mathrm{n}(\%)\end{array}$ & $23(5.36)$ & I5 (I0.7I) & $3(9.37)$ & $\begin{array}{l}P=0.045^{\mathrm{a}, \mathrm{b}} \\
P=0.58 \mathrm{I}^{\mathrm{a}, \mathrm{c}} \\
P=0.960^{\mathrm{b}, \mathrm{c}}\end{array}$ \\
\hline $\begin{array}{l}\text { Recurrent in-hospital } \\
\text { MI, n (\%) }\end{array}$ & $26(6.06)$ & $19(13.57)$ & $4(12.50)$ & $\begin{array}{l}P=0.007^{\mathrm{a}, \mathrm{b}} \\
P=0.292^{\mathrm{a}, \mathrm{c}} \\
P=0.960^{\mathrm{b}, \mathrm{c}}\end{array}$ \\
\hline Stroke, n (\%) & I $(0.23)$ & $0(0)$ & $0(0)$ & $\begin{array}{l}P=0.960^{\mathrm{a}, \mathrm{b}} \\
P=0.960^{\mathrm{a}, \mathrm{c}} \\
P=0.960^{\mathrm{b}, \mathrm{c}}\end{array}$ \\
\hline
\end{tabular}

Notes: agroup with normal glucose. bgroup with diabetes mellitus. 'group with impaired glucose tolerance.

Abbreviations: DM, diabetes mellitus; IGT, impaired glucose tolerance; MI, myocardial infarction; STEMI, ST segment elevation myocardial infarction.
Table 5 End points within I year after STEMI with regard to carbohydrate metabolism disorders $(n=470)$

\begin{tabular}{|c|c|c|c|c|}
\hline End points & $\begin{array}{l}\text { Normal } \\
\text { glucose }^{a} \\
(n=429)\end{array}$ & $\begin{array}{l}D^{b} \\
(n=\mid 40)\end{array}$ & $\begin{array}{l}I^{\prime G T^{c}} \\
(n=32)\end{array}$ & $P$-value \\
\hline $\begin{array}{l}\text { Composite end } \\
\text { point, } n(\%)\end{array}$ & $92(28.84)$ & $52(43.70)$ & II (36.67) & $\begin{array}{l}P=0.005^{a, b} \\
P=0.491^{a, c} \\
P=0.624^{b, c}\end{array}$ \\
\hline Death, n (\%) & $39(12.22)$ & $18(15.12)$ & $2(6.67)$ & $\begin{array}{l}P=0.520^{a, b} \\
P=0.544^{a, c} \\
P=0.360^{b, c}\end{array}$ \\
\hline MI, n (\%) & 49 (I5.36) & 31 (26.05) & $6(20.0)$ & $\begin{array}{l}P=0.015^{a, b} \\
P=0.686^{a, c} \\
P=0.653^{b, c}\end{array}$ \\
\hline Stroke, n (\%) & $8(2.50)$ & $9(7.56)$ & I (3.33) & $\begin{array}{l}P=\left.0.03\right|^{a, b} \\
P=0.960^{a, c} \\
P=0.675^{b, c}\end{array}$ \\
\hline $\begin{array}{l}\text { Unstable angina, } \\
\mathrm{n}(\%)\end{array}$ & $29(9.09)$ & $18(15.13)$ & $5(16.67)$ & $\begin{array}{l}P=\left.0.10\right|^{a, b} \\
P=0.310^{a, c} \\
P=0.960^{b, c}\end{array}$ \\
\hline $\begin{array}{l}\text { CHF worsening, } \\
\mathrm{n}(\%)\end{array}$ & $10(3.14)$ & $9(7.56)$ & I (3.33) & $\begin{array}{l}P=0.078^{a, b} \\
P=0.960^{a, c} \\
P=0.675^{b, c}\end{array}$ \\
\hline $\begin{array}{l}\text { Emergency PCl, } \\
\mathrm{n}(\%)\end{array}$ & $18(5.64)$ & $16(13.45)$ & $6(20.0)$ & $\begin{array}{l}P=0.012^{a, b} \\
P=0.009^{a, c} \\
P=0.538^{b, c}\end{array}$ \\
\hline
\end{tabular}

Notes: agroup with normal glucose. bgroup with diabetes mellitus. 'group with impaired glucose tolerance.

Abbreviations: CHF, congestive heart failure; DM, diabetes mellitus; IGT, impaired glucose tolerance; $\mathrm{MI}$, myocardial infarction; $\mathrm{PCl}$, percutaneous coronary intervention; STEMI, ST segment elevation myocardial infarction.

\section{Discussion}

First, DM MI patients were more effectively treated than were those with normal blood glucose. This effect was likely due to the higher absolute risk for cardiovascular events in DM MI patients, which results in a higher therapeutic benefit. ${ }^{19}$

However, the negative impact of DM on the outcomes of MI patients should also be considered when PCI is performed, which has also been demonstrated in this manuscript. ${ }^{5}$ Indeed, despite encouraging results, a history of DM remains a risk factor for early and late events after primary PCI. ${ }^{6} \mathrm{DM}$ patients have been proven to have a high risk of restenosis and repeat revascularization. ${ }^{20} \mathrm{DM}$ patients have higher rates of atherosclerosis progression both in revascularized and nonrevascularized areas. ${ }^{21}$

In a previous study, we obtained data that confirmed a negative impact of IGT on MI prognosis similar to that of DM. ${ }^{7}$ Diabetic patients with chronic hyperglycemia and dyslipidemia typically have signs of active intravascular inflammation is a prerequisite for higher rates of atherosclerosis progression in addition to increased platelet activity, which is also typical of diabetic patients. ${ }^{22}$ These relationships should be considered when discussing the mechanisms of a favorable prognosis in patients with IGT. 
Table 6 One-year outcome in the groups with regard to PCl and IGT

\begin{tabular}{|c|c|c|c|c|c|}
\hline \multirow{2}{*}{$\begin{array}{l}\text { I-year } \\
\text { outcomes }\end{array}$} & \multicolumn{2}{|l|}{ No PCl } & \multicolumn{2}{|l|}{$\mathrm{PCl}$} & \multirow[t]{2}{*}{$P$-value } \\
\hline & $\begin{array}{l}\text { Carbohydrate } \\
\text { metabolism disorders }\end{array}$ & $\begin{array}{l}\text { Normal blood } \\
\text { glucose }\end{array}$ & $\begin{array}{l}\text { Carbohydrate } \\
\text { metabolism disorders }\end{array}$ & $\begin{array}{l}\text { Normal blood } \\
\text { glucose }\end{array}$ & \\
\hline Good outcome, \% & 51.56 & 54.26 & 63.22 & 78.22 & $\begin{array}{l}\leq 0.00 I^{*} \\
\leq 0.00 I^{* *}\end{array}$ \\
\hline Poor outcome, \% & 48.44 & 45.74 & 36.78 & 21.28 & $\geq 0.05$ \\
\hline
\end{tabular}

Notes: *Significant differences between normal blood glucose $(\mathrm{PCl})$ and carbohydrate metabolism disorders (PCl). **Significant differences between normal blood glucose (no $\mathrm{PCl}$ ) and normal blood glucose (PCl).

Abbreviations: IGT, impaired glucose tolerance; $\mathrm{PCl}$, percutaneous coronary intervention.

In a previous work, the authors demonstrated that both MI patients with DM and those with IGT have a high proinflammatory potential, which is manifested in the increased levels of CRP, IL-12, and SCD40L. Therefore, inflammation can be regarded as the leading mechanism of the manifestation of adverse vascular events in patients with both symptomatic and subclinical IGT. ${ }^{10}$

In the current study IL-12 played an important role in the risk assessment of adverse events in both CMD and normal glucose patients. The function of IL-12 as an inflammation marker in atherosclerosis is unclear, and most relevant studies have been experimental. IL-12 and IL-18 have been established as powerful inducers of interferon gamma (IFN- $\gamma$ ) production, ${ }^{23}$ a proinflammatory cytokine that accelerates atherosclerosis progression. ${ }^{24}$ This cytokine produced by macrophages was found to cause undifferentiated CD4+ cells to differentiate into T helper (Th) 1 cells, which help define the cells responsible for specific immune system response by means of IL-2, IFN- $\gamma$, TNF- $\alpha$, and the CD 40 ligand. ${ }^{25}$

A previous immunohistochemical study showed increased IL-12 levels in human atherosclerotic plaques compared with normal arteries. ${ }^{26}$ Another study demonstrated the role of IL-12 in murine atherosclerosis development and progression. ${ }^{27}$ In an earlier study, the authors found that IL-12 also played a very important role in predicting vascular events in STEMI patients within the 1-year follow-up period. ${ }^{28}$ This marker remained important to predict the outcomes after MI, both in the patients with and

Table 7 Inflammation markers in STEMI patients with regard to carbohydrate metabolism disorders

\begin{tabular}{|c|c|c|c|c|}
\hline Inflammation markers & Normal glucose $^{a}(n=429)$ & $\mathrm{DM}^{\mathrm{b}}(\mathrm{n}=140)$ & $\operatorname{IGT}^{\mathrm{c}}(\mathrm{n}=32)$ & $P$-value \\
\hline \multirow[t]{3}{*}{ Fibrinogen, g/L } & $3.2(2.58 ; 4.2)$ & $3.75(2.84 ; 6.05)$ & $3.5(2.34 ; 5.08)$ & $P=0.005^{a, b}$ \\
\hline & & & & $P=0.493^{\mathrm{a}, \mathrm{c}}$ \\
\hline & & & & $P=0.308^{b, c}$ \\
\hline \multirow[t]{3}{*}{ TNF- $\alpha, p g / m L$} & 9.61 (7.24; II.99) & $9.32(6.16 ; 13.68)$ & 9.75 (7.05; 12.79) & $P=\left.0.87\right|^{a, b}$ \\
\hline & & & & $P=0.534^{a, c}$ \\
\hline & & & & $P=0.727^{b, c}$ \\
\hline \multirow[t]{3}{*}{ IL-10, pg/mL } & $1.78(1.06 ; 2.72)$ & $2.13(1.22 ; 3.31)$ & $1.98(1.15 ; 3.05)$ & $P=0.528^{a, b}$ \\
\hline & & & & $P=0.204^{a, c}$ \\
\hline & & & & $P=0.215^{b, c}$ \\
\hline \multirow[t]{3}{*}{ IL-8, pg/mL } & $3.35(1.65 ; 5.73)$ & $3.24(1.88 ; 5.84)$ & $3.53(1.74 ; 5.96)$ & $P=0.810^{a, b}$ \\
\hline & & & & $P=0.450^{a, c}$ \\
\hline & & & & $P=0.376^{\mathrm{b}, \mathrm{c}}$ \\
\hline \multirow[t]{3}{*}{$\mathrm{IL}-6, \mathrm{pg} / \mathrm{mL}$} & $2.05(0.44 ; 5.68)$ & $4.75(0.79 ; 7.46)$ & $3.97(0.56 ; 6.49)$ & $P=0.023^{a, b}$ \\
\hline & & & & $P=0.039^{a, c}$ \\
\hline & & & & $P=0.278^{b, c}$ \\
\hline \multirow[t]{3}{*}{ IL-12, pg/mL } & 99.0 (64.07; I 20.3) & $109.50(95.63 ; 128.0)$ & I 22.5 (I07.30; I33.50) & $P=0.152^{a, b}$ \\
\hline & & & & $P=0.017^{a, c}$ \\
\hline & & & & $P=0.032^{b, c}$ \\
\hline \multirow[t]{3}{*}{$\mathrm{CRP}, \mathrm{mg} / \mathrm{L}$} & II.95 (6.57; 19.75) & $13.10(5.52 ; \mid 8.0)$ & $12.03(5.47 ; 17.56)$ & $P=0.687^{a, b}$ \\
\hline & & & & $P=0.785^{a, c}$ \\
\hline & & & & $P=0.432^{b, c}$ \\
\hline \multirow[t]{3}{*}{$\mathrm{sCD} 40 \mathrm{~L}, \mathrm{ng} / \mathrm{mL}$} & $4.85(2.16 ; 8.42)$ & $8.30(5.77 ; 10.44)$ & $7.87(3.55 ; 9.79)$ & $P=\left.0.03\right|^{a, b}$ \\
\hline & & & & $P=0.045^{a, c}$ \\
\hline & & & & $P=0.308^{b, c}$ \\
\hline
\end{tabular}

Notes: Values are presented as median (QI:Q3). a group with normal glucose. 'broup with diabetes mellitus. 'group with impaired glucose tolerance.

Abbreviations: CRP, c-reactive protein; DM, diabetes mellitus; IGT, impaired glucose tolerance; IL, interleukin; sCD40L, CD40 ligand; STEMI, ST segment elevation myocardial infarction; TNF, tumor necrosis factor; Q, interquartile range. 
Table 8 Factors associated with poor I-year outcome

\begin{tabular}{|c|c|c|c|}
\hline Parameters & Odds ratio & $95 \% \mathrm{Cl}$ & $P$-value \\
\hline \multicolumn{4}{|l|}{ Normal glucose } \\
\hline Female-to-male ratio & 1.97 & $1 . \mid 7-3.31$ & 0.008 \\
\hline $\begin{array}{l}\text { Ratio of the patients older } \\
\text { and younger than } 70 \text { years }\end{array}$ & 3.77 & $2.24-6.35$ & $<0.0001$ \\
\hline History of $\mathrm{MI}$ & 1.86 & $1.08-3.22$ & 0.020 \\
\hline History of angina pectoris & 2.02 & $1.23-3.32$ & 0.007 \\
\hline History of stroke & 2.67 & $1.11-6.39$ & 0.009 \\
\hline LVEF $<46 \%$ & 3.81 & $2.26-6.45$ & $<0.000$ I \\
\hline Ratio of Killip II-IV and I & 3.21 & $|.8|-5.7 \mid$ & $<0.000$ I \\
\hline \multicolumn{4}{|l|}{ of $>7.8 \mathrm{mmol} / \mathrm{L}$} \\
\hline $\mathrm{PCl}$ & 0.33 & $0.20-0.55$ & $<0.000$ I \\
\hline Recurrent in-hospital MI & 3.20 & $0.84-7.21$ & 0.029 \\
\hline TNF- $\alpha>14.12 \mathrm{pg} / \mathrm{mL}$ & 4.73 & $1.93-11.58$ & 0.0001 \\
\hline IL-6 $>8.05$ pg/mL & 3.14 & I.29-7.67 & 0.007 \\
\hline $\mathrm{IL}-12>110.01 \mathrm{pg} / \mathrm{mL}$ & 5.18 & I.54-7.37 & 0.009 \\
\hline \multicolumn{4}{|l|}{ Diabetes mellitus } \\
\hline History of chronic heart failure & 3.71 & $0.67-8.40$ & 0.039 \\
\hline LVEF $<46 \%$ & 4.01 & $1.35-8.37$ & 0.034 \\
\hline Ratio of Killip II-IV and I & 3.51 & $1.31-7.05$ & 0.041 \\
\hline $\mathrm{PCl}$ & 0.23 & $0.15-0.69$ & 0.039 \\
\hline $\mathrm{IL}-12>110.01 \mathrm{pg} / \mathrm{mL}$ & 5.57 & $1.01-9.34$ & 0.033 \\
\hline \multicolumn{4}{|l|}{ Impaired glucose tolerance } \\
\hline History of angina pectoris & 1.37 & $0.6 \mathrm{I}-3.09$ & 0.044 \\
\hline $\mathrm{PCl}$ & 0.20 & $0.10-0.63$ & 0.022 \\
\hline $\begin{array}{l}\text { Admission glucose } \\
\text { of }>7.8 \mathrm{mmol} / \mathrm{L}\end{array}$ & 1.93 & $0.43-8.61$ & 0.038 \\
\hline $\mathrm{IL}-12>110.01 \mathrm{pg} / \mathrm{mL}$ & 4.74 & $1.12-6.17$ & 0.024 \\
\hline
\end{tabular}

Abbreviations: $\mathrm{Cl}$, confidence interval; IL, interleukin; LVEF, left ventricular ejection fraction; $\mathrm{MI}$, myocardial infarction; $\mathrm{PCl}$, percutaneous coronary intervention; TNF, tumor necrosis factor.

without a history of CMD in this study. Thus, IL-12 might be an independent marker of atherosclerosis progression.

Another cytokine examined in this study, IL-6, could discriminate patients at a high risk for new vascular accidents within 1 year after MI treated with an invasive approach. The prognostic value of IL- 6 has been demonstrated in population epidemiology studies. ${ }^{29,30}$ In one study, increased IL-1 and IL-6 were confirmed to be associated with recurrent coronary events in IHD patients. ${ }^{31}$ Martins et al showed significant increases in IL-2, IL-4, IL-6, IL-12, and IL-18 in IHD patients compared with healthy subjects, and the levels of IL-6 were much higher in MI patients. ${ }^{32}$ Kubensky et $\mathrm{al}^{33}$ assessed the concentrations of inflammation markers in patients with Q-wave MI, at days 2-10: higher IL-6 and TNF- $\alpha$ levels were observed if the MI course was complicated. Kopitsa ${ }^{34}$ showed that IL-6 $>180 \mathrm{pg} / \mathrm{mL}$ at days $4-6$ from the acute MI onset was a highly sensitive but less specific marker for recurrent coronary events and sudden coronary death in this category of patients. Meanwhile, Orlova ${ }^{35}$ demonstrated that only extremely low admission IL-6 levels were predictors of hospital mortality in patients with acute Q-wave MI compared with the other inflammation markers under study (CRP, IL-6, IL-8, IL-12, and IL-10).

Previously published data support the association between the increase in TNF- $\alpha$ and recurrent coronary events in IHD patients. ${ }^{36}$ The Cholesterol and Recurrent Events (CARE) study demonstrated that increased expression of TNF- $\alpha 9$ months after MI was a predictor of high risk of coronary events within a 5-year follow-up period. ${ }^{37}$ The results of this study showed the role of this marker in the prediction of adverse outcomes in MI patients who underwent PCI. The latest studies have found that TNF- $\alpha$ and IL- 6 produced in the adipose tissue could influence the peripheral tissue sensitivity to insulin..$^{38,39}$

Studying the role of proinflammatory cytokines (TNF- $\alpha$, IL-6, and CRP) and their impact on the vascular complications of DM has suggested that inflammation plays a specific role in the development of insulin resistance. Chronic subclinical inflammation is thought to be a part of insulin resistance syndrome, and the aforementioned cytokines are predictors of vascular DM complications. ${ }^{38,39}$ Hyperglycemia was confirmed to be one of the main stimuli for the expression of inflammation markers by endothelial cells. ${ }^{40}$ Convincing experimental and clinical study has confirmed the role of hyperglycemia in the increase in CRP, IL-6, and TNF- $\alpha$ levels. ${ }^{40}$ Additionally, hyperglycemia enhances the release of reactive oxygen, which can cause a more severe oxidative stress than chronic hyperglycemia, if glucose levels change dramatically. ${ }^{41}$

The results of this study showed the role of inflammation as a general pathogenetic link in atherogenesis, atherothrombosis (MI), and CMD development, which confirmed the association between these conditions and the need for proinflammatory status assessment to stratify the risk of MI patients. Thus, persistent inflammation in STEMI patients with CMD undergoing PCI might be responsible for vascular accidents within 1 year after MI. Comorbid DM or IGT can amplify the significance of the inflammatory response for the development of adverse 1-year outcomes.

\section{Disclosure}

The authors report no conflicts of interest in this work.

\section{References}

1. Bartnik M, Ryden L, Ferrari R, et al; Euro Heart Survey Investigators. The prevalence of abnormal glucose regulation in patients with coronary artery disease across Europe. The Euro Heart Survey on diabetes and the heart. Eur Heart J. 2004;25:1880-1890.

2. Barr EL, Zimmet PZ, Welborn TA, et al. Risk of cardiovascular and allcause mortality in individuals with diabetes mellitus, impaired fasting glucose, and impaired glucose tolerance: the Australian Diabetes, Obesity, and Lifestyle Study (AusDiab). Circulation. 2007;116(2): 151-157. 
3. Haffner SM. Management of dyslipidemia in adults with diabetes. Diabetes Care. 2003;26(Suppl 1):S83-S86.

4. Fei GZ, Huang YH, Swedenborg J, Frostegård J. Oxidised LDL modulates immune-activation by an IL-12 dependent mechanism. Atherosclerosis. 2003;169(1):77-85.

5. Belenkova YA, Tavlueva EV, Karetnikova VN, et al. [Prognosis in patients with ST segment elevation myocardial infarction, in regard to the presence of Type 2 diabetes mellitus and selected treatment strategy in the acute period]. Russian Journal of Cardiology. 2012;5(97):17-24 Russian.

6. Goto K, Shiode N, Shirota K, et al. Impact of impaired renal function and diabetes on long-term prognosis in patients undergoing primary angioplasty for acute coronary syndrome. Intern Med. 2008;47(10): 907-913.

7. Karetnikova VN, Barbarash OL, Kvitkova LV, et al. [Early revealing of disturbances of the carbohydrate metabolism - the important marker of the long-time prognosis at the myocardial infarction]. Pathology of Circulation and Heart Surgery. 2010;2:33-37. Russian.

8. Otsuka F, Hibi K, Kusama I, et al. Impaired glucose tolerance is associated with positive coronary artery remodeling in non-diabetic patients with ST-elevation acute myocardial infarction. Circulation. 2008;118:S_1113. Abstract.

9. Lowe GD, Sweetnam PM, Yarnell JW, et al. C-reactive protein, fibrin D-dimer, and risk of ischemic heart disease. The Caerphilly and Speedwell Studies. Arterioscler Thromb Vasc Biol. 2004;24(10): 1957-1962.

10. Karetnikova VN, Gruzdeva OV, Barbarash OL. [The role of markers of inflammation in assessment of prognosis in patients with ST-elevation myocardial infarction combined with disturbances of carbohydrate metabolism]. Kardiologiia. 2012;52(8):20-26. Russian.

11. World Medical Association, Inc. WMA Declaration of Helsinki - Ethical Principles for Medical Research Involving Human Subjects. Ferney-Voltaire: World Medical Association, Inc; 2008. Available from: http://www. wma.net/en/30publications/10policies/b3/. Accessed January 1, 2015.

12. American Diabetes Association. Diagnosis and classification of diabetes mellitus. Diab Care. 2011;34(1):S62-S69.

13. National Society of Cardiology. Diagnosis and treatment of patients with acute myocardial infarction with ST-segment elevation electrocardiogram: Russian recommendations. Moscow; 2007.

14. Sianos G, Morel MA, Kappetein AP, et al. The SYNTAX Score: an angiographic tool grading the complexity of coronary artery disease. EuroInterv. 2005;1:219-227.

15. Sianos G, Morel MA, Kappetein AP, et al. The SYNTAX Score: an angiographic tool grading the complexity of coronary artery disease. EuroIntervention. 2005;1(2):219-227.

16. SYNTAX score calculator [homepage on the Internet]. Available from: http://www.syntaxscore.com/calc/start.htm. Accessed October 23, 2014.

17. TIMI study group [homepage on the Internet]. TIMI Risk Score Calculator. Available from: http://www.timi.org/index.php?page=calculators. Accessed October 23, 2014

18. Killip T, Kimball JT. Treatment of myocardial infarction in a coronary care unit. A two year experience with 250 patients. Am J Cardiol. 1967;20(4):457-464.

19. Donahoe SM, Stewart GC, McCabe CH, et al. Diabetes and mortality following acute coronary syndromes. JAMA. 2007;298(7):765-775.

20. Gilbert J, Raboud J, Zinman B. Meta-analysis of the effect of diabetes on restenosis rates among patients receiving coronary angioplasty stenting. Diabetes Care. 2004;27(4):990-994.

21. Rozenman Y, Sapoznikov D, Mosseri M, et al. Long-term angiographic follow-up of coronary balloon angioplasty in patients with diabetes mellitus: a clue to the explanation of the results of the BARI study Balloon Angioplasty Revascularization Investigation. J Am Coll Cardiol. 1997;30(6):1420-1425.

22. Barbarash OL, Belenkova YA, Karetnikova VN, et al. Role of inflammation in the development of vascular complications after percutaneous coronary intervention in myocardial infarction patients with diabetes. Heart. 2012;3(65):131-136.
23. Munder M, Mallo M, Eichmann K, Modolell M. Murine macrophages secrete interferon gamma upon combined stimulation with interleukin (IL)-12 and IL-18: A novel pathway of autocrine macrophage activation. J Exp Med. 1998;187(12):2103-2108.

24. Gupta S, Pablo AM, Jiang Xc, Wang N, Tall AR, Schindler C. IFNgamma potentiates atherosclerosis in ApoE knock-out mice. $J$ Clin Invest. 1997;99(11):2752-2761.

25. Packard RR, Libby P. Inflammation in atherosclerosis: from vascular biology to biomarker discovery and risk prediction. Clin Chem. 2008; $54(1): 24-38$.

26. Uyemura K, Demer LL, Castle SC, et al. Cross-regulatory roles of interleukin (IL)-12 and IL-10 in atherosclerosis. J Clin Invest. 1996;97(9):2130-2138.

27. Lee TS, Yen HC, Pan CC, Chau LY. The role of interleukin 12 in the development of atherosclerosis in ApoE-deficient mice. Arterioscler Thromb Vasc Biol. 1999;19(3):734-742.

28. Barbarash OL, Zykov MV, Kashtalap VV, Osokina AV, Berns SA, Karetnikova VN. [Prognostic value of various markers of inflammation in ST-elevation myocardial infarction]. Kardiologiia. 2011;51(3):24-30. Russian.

29. Ridker PM, Rifai N, Stampfer MJ, Hennekens CH. Plasma concentration of interleukin- 6 and the risk of future myocardial infarction among apparently healthy men. Circulation. 2000;101(15): 1767-1772.

30. Volpato S, Guralnik JM, Ferrucci L, et al. Cardiovascular disease, interleukin-6, and risk of mortality in older women. The women's health and aging study. Circulation. 2001;103(7):947-953.

31. Biasucci LM, Luizzo G, Fantuzzi G, et al. Increasing levels of interleukin (IL)-1Ra and IL-6 during the first 2 days of hospitalization in unstable angina are associated with increased risk of in-hospital coronary events. Circulation. 1999;99(16):2079-2084.

32. Martins TB, Anderson JL, Muhlestein JB, et al. Risk factor analysis of plasma cytokines in patients with coronary artery disease by a multiplexed fluorescent immunoassay. Am J Clin Pathol. 2006;125(6): 906-913.

33. Kubensky GE, Chernov SA, Skvortsov SV, et al. [Assessment of changes in cytokine levels, serum neopterin and C-reactive protein in patients with myocardial infarction]. Russian Journal of Cardiology. 2005;5:12-15. Russian.

34. Kopitsa NP. [Interleukin- 6 and the incidence of sudden cardiac death in post-MI patients]. Visn Hark Nat University. 2004;61:31-34. Russian.

35. Orlova NV. [Inflammation and risk factors for cardiovascular disease] [PhD thesis]. Moscow: Russian State Medical University; 2008. Russian.

36. Amar J, Fauvel J, Drouet L, et al. Interleukin 6 is associated with subclinical atherosclerosis: a link with soluble intercellular adhesion molecule 1. J Hypertens. 2006;24(6):1083-1088.

37. Lewis SJ, Moye LA, Sacks FM, et al. Effect of pravastatin on cardiovascular events in older patients with myocardial infarction and cholesterol levels in the average range. Results of the Cholesterol and Recurrent Events (CARE) trial. Ann Intern Med. 1998;129(9):681-689.

38. Festa A, D'Agostino R, Howard G, Mykkänen L, Tracy RP, Haffner SM. Chronic subclinical inflammation as part of the insulin resistance syndrome: the Insulin Resistance Atherosclerosis Study (IRAS). Circulation. 2000;102(1):42-47.

39. Festa A, D'Agostino R, Tracy RP, Haffner SM; Insulin Resistance Atherosclerosis Study. Elevated levels of acute-phase proteins and plasminogen activator inhibitor-1 predict the development of type 2 diabetes: the insulin resistance atherosclerosis study. Diabetes. 2002;51(4):1131-1137.

40. Chazova TE, Masenko VP, Zykov KA, Golitsyna TIu. [The role of inflammation factors in development of acute coronary syndrome in patients with type 2 diabetes mellitus and impaired glucose tolerance]. Ter Arkh. 2007;79(6):60-64. Russian.

41. Fleischman A, Shoelson SE, Bernier R, Goldfine AB. Salsalate improves glycemia and inflammatory parameters in obese young adults. Diabetes Care. 2008;31(2):289-294. 
Journal of Inflammation Research

Dovepress

\section{Publish your work in this journal}

The Journal of Inflammation Research is an international, peer-reviewed open-access journal that welcomes laboratory and clinical findings on the molecular basis, cell biology and pharmacology of inflammation including original research, reviews, symposium reports, hypothesis formation and commentaries on: acute/chronic inflammation; mediators of inflamma-

tion; cellular processes; molecular mechanisms; pharmacology and novel anti-inflammatory drugs; clinical conditions involving inflammation. The manuscript management system is completely online and includes a very quick and fair peer-review system. Visit http://www.dovepress.com/ testimonials.php to read real quotes from published authors.

Submit your manuscript here: http://www.dovepress.com/journal-of-inflammation-research-journal 